\title{
Capítulo 3 \\ LEITURA LITERÁRIA E CONHECIMENTO LINGUÍSTICO: CAMINHOS QUE SE ENTRECRUZAM
}

Ernani Terra (UPM)

o presente capítulo se inscreve num quadro teórico que procura problematizar o ensino de literatura a partir do texto literário, tomando como referência o que propõem os Parâmentros Curriculares Nacionais (PCNs).

Nunca é demais lembrar que diferentes pesquisadores de filiações teóricas as mais diversas têm emprestado sua contribuição, apresentando práticas que tornam as orientações dos PCNs exequíveis. Este texto vem se somar à literatura já existente, contribuindo para enriquecer o debate sobre o tema. As reflexões apresentadas sobre práticas de ensino de literatura têm por finalidade mostrar uma abordagem que permite integrar o ensino de língua com o de literatura.

Se o ensino deve pautar-se pela interdisciplinaridade, com mais razão, essa deve estar presente entre disciplinas de uma mesma área de conhecimento. Partimos do pressuposto de que o objetivo do ensino de Literatura deve ter sempre por objeto o discurso literário, materializado em textos de diversos gêneros. Nossa proposta está de acordo com os PCNs, que postulam que " $a$ unidade básica da linguagem verbal é o texto, compreendido como a fala e o discurso que o produz..." (BRASIL, 2000, p. 18). O texto deve ser visto como ponto de partida para se compreender suas condições de produção e não o inverso, como é praxe em nossa tradição escolar.

Como suporte teórico para estabelecer os procedimentos envolvidos na leitura de textos literários, recorremos aos estudos de Émile Benveniste sobre as categorias da enunciação e a Dominique Maingueneau no tange ao discurso literário. Em vários momentos deste trabalho, procuramos integrar essas duas teorias.

Temos por objetivo fornecer aos professores-leitores orientações teórico-metodológicas que lhes possam servir de parâmetros para o ensino de literatura a partir da leitura de textos representativos, integrando-o ao ensino de língua. 


\section{Contextualizando o problema}

Com a Lei de Diretrizes de Bases (LDB $\left.n^{0} 5692 / 71\right)$, os estudos de lingua materna se dicotomizaram em duas disciplinas autônomas: língua e literatura, com ênfase na brasileira. Em diversas instituições de ensino, houve (e ainda há) até uma divisão triádica, e passamos a ter três eixos que, embora relacionados epistemologicamente, passaram a receber tratamento autônomo, em muitos casos, com professores distintos. A divisão língua, literatura e redação, posteriormente denominada produção de texto, estava implantada. Os exames seletivos adotaram essa tripartição. Os livros escolares, idem.

Do ponto de vista pedagógico, a tripartição não deve ser vista como ruim, se o traço comum que permeia essas frentes, a linguagem verbal, for o eixo organizador da prática pedagógica. Infelizmente, não foi isso a que se assistiu. Implantada a tripartição, a fenda entre as disciplinas foi progressivamente aumentando, a ponto de o Ensino Médio chegar a ter professores "especialistas" em cada uma das frentes.

Quanto à língua portuguesa, salvo poucas exceções, o foco continuou a ser a gramática da frase, com sua nomenclatura específica. Texto e discurso são organizações transfrásticas. Uma abordagem da lingua que se situe no nível da frase não tem o condão de possibilitar aos alunos o desenvolvimento de competências textuais e discursivas.

o estudo da literatura, em vez de se centrar no texto literário, continuou focalizado em sua história, com seus estilos de época, autores e obras. Ressaltamos que essa abordagem historicizante já havia sido deixada de lado desde a segunda metade do século passado por diversas correntes teóricas como a Nova Crítica e o Estruturalismo. Esse tipo de abordagem tem por consequência que excelentes autores de nossa literatura contemporânea acabam ficando fora do cânone escolar, não dando oportunidade de que escritores como Milton Hatoum, Patrícia Melo, Lourenço Mutarelli, Marçal Aquino, José Luiz Passos, Bernardo Carvalho, Luiz Ruffato, Michel Laub, Mia Couto, Valter Hugo Mãe, Augustina Bessa Luis, Ondjaki, sejam lidos no âmbito da escola. Tais autores só serão eventualmente lidos se constarem da lista de obras exigidas pelos vestibulares. Sobre a leitura de autores contemporâneos, já sustentávamos que

como o ensino de literatura na escola, privilegia a história da literatura, destacando os chamados estilos de época (Barroco, Arcadismo, Romantismo etc.), o professor sente-se inseguro ao tratar desses autores, por não conseguir encaixá-los em nenhuma das "correntes literárias" estudadas no tradicional modo histórico-cultural de abordar a literatura. (TERRA,2014, p. 28)

Na escola, a leitura do texto literário é feita normalmente para exemplificar características do autor ou do período e não costuma estar centrada nos procedimentos linguísticos que constroem seu sentido, como bem atestam os PCNs, ao afirmarem que "a história da literatura costuma ser o foco da compreensão do texto, uma história que nem sempre lhe serve de exemplo" (BRASIL, 2000, p.16).

Dentro desse quadro, não propomos o fim da tripartição, nem que o professor de língua passe a ensinar literatura, ou vice-versa, mas uma integração dos estudos linguísticos com os literários, tendo como ponto de partida o texto. Os estudos gramaticais e a história da literatura devem ser deixados em segundo plano. A gramática deve ser articulada com as estratégias de compreensão e produção textual, servindo-lhe de suporte, e a literatura, integrada à área de leitura.

\section{Um dos eixos de integração}

Uma das formas para integrar os estudos literários como os linguísticos é trabalhar com os estudantes as formas pelas quais o enunciador se instala no texto e quais recursos de linguagem permitem ao leitor dar conta do contexto de produção. Maingueneau enfatiza que

as teorias da enunciação linguística atribuem papel essencial à reflexividade da atividade discursiva e de modo particular às coordenadas implicadas por todo ato de 
enunciação: coordenadas pessoais, espaciais e temporais nas quais se baseia a referência de tempo dêitico. (2006, p. 249)

o estudo das categorias da enunciação (ego-hic-nunc) permite que os professores trabalhem não só os efeitos de sentido do discurso (maior ou menor subjetividade, por exemplo), como também noções linguísticas de pessoa e tempo verbal, uso de advérbios e demonstrativos, recursos discursivos como referenciação, anáfora e dêixis.

Um texto sem marcas do enunciador tem efeito de sentido de objetividade, daí ser o preferido de autores naturalistas; nos românticos, deparamo-nos, com frequência, com as marcas do enunciador, já que a subjetividade é marca característica desses autores, portanto a escolha de um procedimento ou outro decorre das intenções do enunciador. o que estamos propondo é, ao invés de falar que românticos são subjetivos e naturalistas, objetivos, mostrar como os efeitos de sentido de objetividade e subjetividade são construídos nos textos.

\section{A enunciação}

Saussure nos mostra que a linguagem humana tem um lado individual e um lado social, sendo impossível conceber um sem o outro. Ao lado social e abstrato ele chama língua (langue). Ao lado individual e concreto, denomina fala (parole). Se Saussure distinguiu com bastante propriedade língua e fala, Benveniste o ultrapassa e nos mostra como se passa da língua para a fala. Benveniste denomina enunciação ao processo pelo qual os falantes se apropriam da língua e a convertem em atos de fala, os enunciados.

Enunciação e enunciado são palavras correspondentes ao verbo enunciar. Nelas, temos o radical latino nunci-, o mesmo que aparece em anunciar, denunciar, pronunciar. Enunciar significa dizer; portanto enunciado é aquilo que se diz, o dito, e enunciação é o ato de dizer. A enunciação não se confunde com o texto (o enunciado), ela é o ato pelo qual os falantes produzem enunciados. Há aí uma implicação lógica: a enunciação é pressuposta pelo enunciado, ou seja, se há um dito (o enunciado), pressupõe-se logicamente que houve um ato de dizer (a enunciação). Maingueneau (2006) afirma que a enunciação ocupa um espaço entre texto e contexto e que, entre o espaço de produção e o espaço textual, há a cena da enunciação.

Benveniste nos mostra ainda que a enunciação frequentemente deixa marcas no enunciado e que ela tem um conteúdo linguístico. Para ele, pela enunciação instala-se o sujeito no enunciado. Instalado um eu (ego), instalam-se também um lugar (hic) e um tempo (nunc). A enunciação é, pois, a instalação de um ego-hic-nunc, ou seja, de uma pessoa, de um lugar e um tempo. A essas instâncias, Benveniste denominou de aparelho formal da enunciação.

Benveniste escreveu em latim (ego-hic-nunc), e não em francês, língua na qual foram escritos os Problemas de Linguística Geral, para deixar claro que tais categorias não são de uma língua em particular, mas da linguagem humana. Vale lembrar que "as formas de subjetividade supostas pela enunciação é um dos grandes eixos da análise do discurso" (MAINGUENEAU, 2006, p. 42). Esse autor sustenta que a enunciação faz criar um centro dêitico, que é "fonte de pontos de referência de pessoa, tempo e espaço; mas supõe também a atribuição da responsabilidade dos enunciados a diversas instâncias usadas na enunciação" (IBIDEM).

\section{A categoria de pessoa}

Fixemo-nos inicialmente no conceito de pessoa do discurso. Nossos alunos vêm do Ensino Fundamental sabendo que as pessoas do discurso são três: eu-tu-ele (no plural: nós-vós-eles). Benveniste vai nos mostrar que, na verdade, há apenas duas pessoas: o eu e o tu, o enunciador e o co-enunciador, para Maingueneau. O ele não é uma pessoa do discurso, pois não participa da interlocução; não está, portanto, no espaço da enunciação. Não é por acaso que, em árabe, a terceira pessoa é chamada 'aquele que está ausente'. o ele apenas nomeia o referente, por isso Benveniste 
denomina a terceira pessoa de não-pessoa. Sob o ponto de vista da forma, é a única que possui uma forma para o masculino e outra para o feminino (ele / ela) e a única que faz o plural normalmente pelo acréscimo da desinência -s (eles / elas). Ainda: a terceira pessoa é usada quando o predicado não se refere a sujeito algum. Isso demonstra que a terceira pessoa deve ser entendida como uma categoria diferente da primeira e segunda pessoas.

Pela enunciação, o sujeito (eu) se apropria da língua e instaura o discurso. Ao fazê-lo, cria um parceiro a quem se dirige (tu), mesmo que esse não se explicite. Eu e tu são palavras que assumem sentido no discurso. Eu não nomeia um indivíduo, é uma palavra da ordem do discurso, é um signo que não tem referente fixo. Eu é quem diz eu. Tu nomeia aquele a quem o eu se dirige. Eu e tu são reversíveis. Benveniste, ao tratar da natureza dos pronomes afirma que

as instâncias de emprego de eu não constituem uma classe de referência, uma vez que não há "objeto" definível como eu ao qual se possam remeter identicamente essas instâncias. Cada eu tem sua referência própria e corresponde cada vez a um ser único, proposto como tal. [...] eu só pode ser identificado pela instância de discurso que o contém e somente por aí. Não tem valor a não ser na instância na qual é produzido. (BENVENISTE, 1995, p. 278-279)

Perceber a categoria de pessoa é dar conta de que todo discurso é interativo, mesmo que o tu não venha manifestado. Nesse sentido, vale refletir sobre as palavras de Maingueneau (2006, p. 41) "Toda enunciação, mesmo produzida sem a presença de um destinatário, é de fato tomada numa interatividade constitutiva; ela é um intercâmbio, explícito ou implícito, com outros locutores, virtuais ou reais".

o discurso literário, assim como outros discursos, caracteriza-se pela interação, por isso não há sentido algum em ver a obra literária como uma entidade autônoma, fora de um contexto de interlocução. Maingueneau é claro ao afirmar que

Tratando do processo de comunicação da obra literária como um ato de enunciação sujeito, embora de maneira específica, às normas da interação verbal, afastamo-nos da concepção literária vigente desde o romantismo, que julga que a obra constitui um mundo autárquico cuja colaboração ocorre fora de toda consideração de sua recepção. (MAINGUENEAU, 2006, p.75)

Assim como eu e tu, outras categorias gramaticais têm seu sentido dependente da enunciação, como certos pronomes, tempos verbais e alguns advérbios. São os chamados dêiticos, expressões linguísticas cuja interpretação depende da pessoa, do lugar e do momento em que são enunciadas.

\section{A categoria de tempo}

Quando falamos em tempo, estamos nos referindo ao tempo linguístico e não ao tempo físico ou cronológico. Tempo físico é o intervalo entre o início e o fim de um movimento. Usamos, por exemplo, o tempo físico para marcar o dia e o ano, levando em conta a duração do movimento da Terra em torno de seu próprio eixo e em torno do Sol (24 horas e 365 dias, respectivamente). Tempo cronológico é aquele que estabelece uma sucessão a partir de um marco de referência, como o nascimento de Cristo, por exemplo. o tempo cronológico é marcado pelo calendário. o tempo linguístico é aquele que é estabelecido pela enunciação.

o tempo é uma categoria da língua que usamos indicar a posição dos acontecimentos, tomando como referência o momento da enunciação (ME), que é o presente. o tempo linguístico é, portanto, uma categoria dêitica. Em relação ao caráter dêitico dos tempos verbais, Benveniste ressalta que

Poder-se-ia supor que a temporalidade é um quadro inato do pensamento. Ela é produzida, na verdade, na e pela enunciação. Da enunciação procede a instauração da categoria 
do presente, e da categoria do presente nasce a categoria do tempo. o presente é propriamente a origem do tempo. Ele é esta presença no mundo que somente o ato de enunciação torna possível, porque, é necessário refletir bem sobre isso, o homem não dispõe de nenhum outro meio de viver o "agora" e de torná-lo atual senão realizando-o pela inserção do discurso no mundo. (BENVENISTE, 1989, p. 85)

Em função do momento da enunciação (ME), o tempo dos acontecimentos pode ser concomitante, ou não concomitante ao ME. O tempo não concomitante ao ME pode ser anterior ou posterior a ele.

\section{MOMENTO DA ENUNCIAÇÃO (ME)}

CONCOMITANTE NÃO CONCOMITANTE

\begin{tabular}{lll}
\hline & ANTERIOR & POSTERIOR \\
\hline PRESENTE & PASSADO & - \\
\hline
\end{tabular}

Nesse esquema, apresentamos os tempos que têm por referência o ME. Há tempos cujo momento de referência não é o da enunciação, mas um ponto localizado no passado ou no futuro, como o pretérito mais-que-perfeito e o futuro do presente composto, cujos pontos de referência estão instalados num momento passado e num momento futuro, respectivamente. Os tempos cujo momento de referência não seja o ME são chamados tempos relativos, já que são passado ou futuro, em relação a um outro tempo também passado ou futuro. Em vista desse esquema temporal, podemos narrar fatos que são concomitantes, anteriores, ou posteriores ao momento da enunciação.

Abro a porta do quarto. Tudo em ordem. Vou andando pelo corredor, pés descalços. Tudo em ordem. Não há ninguém na casa.

Dou meia-volta, o banheiro, tudo em ordem. Entro no quarto, tranco a porta. Viro-me e vejo um homem ao lado de minha cama. (MELO, 2009, p. 9)

Nesse trecho, em que há marcas de pessoa instalada no texto, temos uma narração em primeira pessoa de um fato concomitante ao momento da enunciação, como se pode notar pelas formas linguísticas dos verbos no presente do indicativo (abro, vou andando, há, dou, entro, tranco, viro, vejo) que marcam uma sucessão dos acontecimentos no tempo (há um antes e um depois). A narração no presente cria um efeito de sentido de realidade, como se os acontecimentos ocorressem na frente do narrador naquele exato momento.

No trecho a seguir, não há marcas do narrador no texto. Temos uma narração em terceira pessoa. É como se os acontecimentos narrassem a si mesmos, o que cria um efeito de sentido de objetividade.

No dia em que o matariam, Santiago Nasar levantou-se às 5h30m da manhã para esperar o navio em que chegava o bispo. Tinha sonhado que atravessava um bosque de grandes figueiras onde caía uma chuva branda, e por um instante foi feliz no sonho, mas ao acordar sentiu-se completamente salpicado de cagadas de pássaros. (MÁRQUEZ, 2007, p. 9)

Trata-se de uma narrativa de fatos não concomitantes ao momento da enunciação. 0 
tempo não é o agora, mas o então. Os acontecimentos narrados estão localizados num momento anterior ao da enunciação, quando ocorreu a morte de Santiago Nasar.

\section{Os tempos verbais}

A partir da observação de como a categoria tempo se instala no enunciado, o professor poderá levar os estudantes a concluir como se dá a arquitetura dos tempos verbais nos textos, em vez de solicitar aos alunos que memorizem paradigmas de conjugação. É fato que os estudantes sabem conjugar e/ou reconhecer determinada forma verbal; mas são, muitas vezes, incapazes de localizar no tempo da narrativa em que momento se situa um acontecimento em relação a outro, o que pode acarretar baixo índice de compreensão.

Lembremos que, nos textos, o tempo é uma construção da linguagem. Para narrar os acontecimentos, o narrador estabelece o momento de referência (MR), que pode estar no presente, no passado ou no futuro.

Hoje de manhã saí muito cedo,

Por ter acordado ainda mais cedo

E não ter nada que quisesse fazer... (PESSOA, 1972, p. 245)

Nesses versos, o momento de referência (MR) é o presente (Hoje).

Ontem à tarde um homem das cidades

Falava à porta da estalagem.

Falava comigo também.

Falava da justiça e da luta para haver justiça

E dos operários que sofrem,

E do trabalho constante, e dos que têm fome,

E dos ricos, que só têm costas para isso. (PESSOA, 1972, p. 220)

Era no tempo do rei.

Uma das quatro esquinas que formam as ruas do Ouvidor e da Quitanda, cortando-se mutuamente, chamava-se nesse tempo - o canto dos meirinhos -; e bem lhe assentava o nome, porque era aí o lugar de encontro favorito de todos os indivíduos dessa classe (que gozava então de não pequena consideração). (ALMEIDA, 2006, p. 65)

Nesses dois trechos, o momento de referência é o passado. No texto de Fernando Pessoa, é marcado pelo dêitico ontem; no de Manuel Antônio de Almeida, pela expressão "Era no tempo do rei". A contextualização leva o leitor a interpretar era no tempo do rei, como a época em que reinava Dom João VI.

Amanhã que é dia dos mortos

Vai ao cemitério. Vai

E procura entre as sepulturas

A sepultura de teu pai. (BANDEIRA, 1974, p. 223)

O momento de referência é o futuro (amanhã).

Em função do MR, os acontecimentos narrados, como vimos, podem ser concomitantes, anteriores ou posteriores. Como há três momentos de referência (presente, passado e futuro), vamos ter nove tempos linguísticos, conforme se observa no esquema a seguir.

MOMENTO DE REFERÊNCIA 


$\begin{array}{ll}\text { PASSADO PRESENTE } & \text { FUTURO }\end{array}$

\author{
passado presente futuro passado presente futuro passado presente futuro
}

\footnotetext{
Não estamos considerando nesse esquema o presente atemporal, aquele que aparece em enunciados que exprimem verdades científicas, como "A soma do quadrado dos catetos é igual ao quadrado da hipotenusa", em que o verbo não situa o fato no tempo.
}

Nas gramáticas escolares, esses tempos são apresentados com uma nomenclatura diferente, muitas vezes incompreensível para os alunos. o passado do passado é chamado de pretérito mais-que-perfeito; o passado do futuro, de futuro de presente composto. Quanto ao passado do passado, ele é chamado de pretérito perfeito ou pretérito imperfeito, se o processo verbal é tomado por inteiro ou em seu curso, respectivamente. Antes de dominar uma nomenclatura específica, é preciso que o aluno identifique o(s) momento(s) de referência e como os tempos se localizam em relação a esse(s) momento(s) e isso só é possível de ser observado em textos. Como a narração situa acontecimentos no tempo linguístico, sua compreensão pressupõe que o leitor identifique a sequencia em que ocorreram, pois nem sempre são expostos na ordem em que sucederam no nível da histórias narrada, pois pode haver anacronias.

o primeiro texto de Fernando Pessoa inicia-se desta forma: "Hoje de manhã saí muito cedo". O MR é o presente (Hoje), que coincide com o ME. Saí é uma forma verbal que exprime um fato anterior ao MR, portanto trata-se do passado do presente, exprimindo processo verbal concluído, que na nomenclatura gramatical recebe o nome de pretérito perfeito.

No segundo texto de Fernando Pessoa, temos:

"Ontem à tarde um homem das cidades

Falava à porta da estalagem."

O MR é o passado (ontem) e falava exprime ação concomitante ao MR, portanto trata-se de um presente do passado que concebe o processo verbal em sua duração. Na nomenclatura gramatical, esse tempo recebe o nome de pretérito imperfeito.

Uma conhecida música de Guilherme Arantes começa assim:

\author{
"Amanhã! \\ Será um lindo dia \\ Da mais louca alegria \\ Que se possa imaginar"
}

O MR está localizado no futuro (amanhã). Será exprime um fato concomitante ao MR, portanto temos um presente do futuro, que na nomenclatura gramatical recebe o nome de futuro do presente. No português brasileiro, é comum usar uma locução formada de verbo ir no presente seguido do infinitivo do verbo principal no lugar do futuro do presente simples, sobretudo quando o acontecimento futuro é tido como certo, como em "Amanhã de manhã / Vou pedir uma café pra nós dois". 
Voltemos ao texto de García Márquez para discutir o emprego de algumas formais verbais. No primeiro enunciado, temos a forma 'matariam', que relata um fato futuro em relação a um momento de referência (MR) instalado no passado ("levantou-se às 5h30min da manhã"). Portanto, é futuro do passado (ou futuro do pretérito, na nomeclatura gramatical). Levantou e chegava exprimem ações passadas, mas como uma diferença quanto ao aspecto dessa ações. Em levantou temos uma ação dada como concluída, como um todo (não há temporalidade interna), não interessando se durou um certo período de tempo ou não; em chegava, a ação expressa uma temporalidade interna, considerando um fragmento de tempo em que se desenrolou. A forma verbal tinha sonhado exprime um fato concluído no passado, mas tendo como momento de referência outro fato também passado (levantou). Como se pode notar, tinha sonhado é um passado do passado, que na nomeclatura gramatical, é chamado de pretérito mais-que-perfeito.

\section{A categoria de espaço}

A instalação da categoria de espaço no enunciado é marcada linguisticamente pelas formas dos pronomes demonstrativos (este-esse-aquele), pelos advérbios de lugar (aqui, aí, lá, cá) e por termos que exercem funções sintáticas de adjunto adverbial de lugar. Ao contrário das categorias de pessoa e de tempo, o espaço pode não estar explicitado no texto.

Se nos reportarmos ao quadro das pessoas do discurso, veremos que os demonstrativos este-esse-aquele e os advérbios aqui-aí-lá se articulam desta forma: os demonstrativos este/esse e os advérbios aqui/aí referem-se ao espação da enunciação, ao passo que o demonstrativo aquele e o advérbio lá, a um espaço fora da enunciação, como no quadro a seguir.

\begin{tabular}{llll} 
Pessoa & & demonstrativo & advérbio \\
\hline la. (eu) & espaço da enunciação & este & aqui \\
\hline 2a. $(\mathrm{tu})$ & & esse & aí
\end{tabular}

não pessoa espaço fora da enunciação

3a.

aquele

lá

Naquele apartamento havia somente cinco móveis: cama, mesa, estante, escrivaninha e cadeira. A escrivaninha, a cadeira e a estante, na verdade se integraram depois. Quando fui morar lá, encontrei apenas uma cama e uma mesa dobrável de alumínio. Havia também uma banheira embutida. Mas não sei se isso conta como móvel. (LUISELLI, 2012, p. 11)

Temos um espaço instalado no texto que não é o espaço da enunciação (o aqui), mas o lá, marcado por expressões como: naquele lugar (adjunto adverbial de lugar), e o advérbio de lugar lá, que retoma anaforicamente, naquele lugar. Se o espaço fosse o da enunciação, não teríamos as formas linguísticas naquele lugar e lá, mas neste lugar e aqui, respectivamente.

Quanto à instalação de pessoa, temos narração em primeira pessoa e quanto ao tempo, temos uma narrativa de um fato anterior à enunciação. 
Todas as tardes a esta casa venho.

Aqui, outrora, sem conchego nobre, Viveu, sentiu e amou este homem pobre

Que carregava canas para o engenho! (ANJOS, 1971, p. 128)

o espaço instalado no texto é o da enunciação, como se pode notar pelas formas linguísticas do pronome demonstrativo esta e do advérbio de lugar aqui.

Quanto à categoria de espaço, Maingueneau (2006) sustenta que o discurso literário revela o pertencimento e o não pertencimento do enunciador a um lugar, introduzindo o conceito de paratopia. "Toda paratopia envolve no mínimo o pertencimento e o não-pertencimento, a inclusão impossível numa 'topia'" (2006, p.109). Maingueneau postula ainda que a noção de paratopia interessa ao discurso literário se for remetida ao contexto e "se for tomada a um só tempo condição e produto do processo criador" (2006, p. 120) e que ela deixa marcas no enunciado. Relativamente à paratopia espacial, Maingueneau afirma que

ela é a de todos os exilados: meu lugar não é meu lugar ou onde estou nunca é meu lugar. Suas grandes figuras são o nômade e o parasita, que trocam constantemente seus poderes. Pretextos para inúmeras obras e colóquios ( "exílio e criação", "literatura de exilados", "o exílio na literatura" etc.), ela pode pode tomar a figura daquele que se recorda de um país de origem ou do nômade, para quem a única origem possível é a mítica. $(2006, \mathrm{p} .110)$

o discurso literário é pleno de situações que revelam o não pertencimento a um lugar, em discursos como os que remetem ao exílio, ao insulamento, à prisão.

\section{As categorias de pessoa, lugar e tempo no texto}

Nesta seção, intentamos mostrar como os conceitos teóricos apresentados podem ser aplicados na leitura de um texto. Tomamos como exemplo um dos poemas mais conhecidos de nossa literatura, a Canção do Exílio, de Gonçalves Dias.

\section{Canção do exílio}

Kennst du das Land, wo die Citronen blühn, Im dunkeln Laub die Gold-Orangen glühn, Kennst du es wohl? Dahin, Dahin! Möcht ich... ziehn!

Goethe

Minha terra tem palmeiras, Onde canta o Sabiá;

As aves que aqui gorjeiam, Não gorjeiam como lá.

Nosso céu tem mais estrelas, Nossas várzeas têm mais flores, Nossas flores têm mais vida, Nossa vida mais amores.

Em cismar sozinho, à noite, Mais prazer encontro eu lá;

Minha terra tem palmeiras, onde canta o Sabiá.

Minha terra tem primores, 


\author{
Que tais não encontro eu cá; \\ Em cismar - sozinho, à noite \\ Mais prazer encontro eu lá; \\ Minha terra tem palmeiras, \\ onde canta o Sabiá.
}

\author{
Não permita Deus que eu morra, \\ Sem que eu volte para lá; \\ Sem que desfrute os primores \\ Que não encontro por cá; \\ Sem qu'inda aviste as palmeiras, \\ Onde canta o Sabiá. \\ Coimbra - julho de 1843.
}

(DIAS, Gonçalves. Canção do exílio. Apud: CANDIDO; CASTELLO, 1973, p.318-319).

A tarefa de leitura de textos em sala de aula deve começar pela reconstituição da cena de enunciação. Lembremos que, se há um enunciado, enunciação e enunciador estão pressupostos. Nos textos em primeira pessoa, o enunciador se manifesta por um narrador, ao qual o enunciador delega uma voz.

No poema, o narrador se instala no texto e deixa nele as marcas de pessoa expressas por pronomes possessivos (minha, nosso, nossas, nossa) e pelo pronome pessoal eu ("Mais prazer encontro eu lá", "Que tais não encontro eu cá", "Não permita Deus que eu morra", "Sem que eu volte para lá"). Não há no texto um narratário (o tu a quem o narrador se dirige) expresso. A instalação de pessoa no texto cria um eixo de coordenadas espácio-temporais (um aqui e um agora). Vejamos agora as categorias tempo e espaço.

o tempo instalado no texto coincide com o da enunciação, ou seja, o agora, o presente do presente, como se pode observar presente do indicativo: tem, canta, gorjeiam, encontro etc., portanto o momento de referência coincide com o da enunciação e apresenta o processo verbal como não concluído, em seu curso. 0 exílio é presente e vivenciado no momento em que dele se fala.

Quanto ao espaço, temos as seguintes formas de advérbios que indicam lugar: aqui, lá e cá. Trata-se de expressões dêiticas e que, portanto, devem ser interpretadas levando em conta a enunciação. Há no paratexto do poema uma informação que possibilita ao leitor recompor o local e a data em que ocorre a enunciação: Coimbra, Portugal, julho de 1843. Essa indicação estabelece um contrato de leitura que orienta o leitor na construção do sentido do poema. Aqui, portanto, deve ser interpretado como Portugal (o topos da enunciação) e lá como Brasil (o topos fora da enunciação). A localização do aqui permite ao leitor atribuir o sentido aos possessivos minha e nossa. Por serem de primeira pessoa, referem-se, portanto, ao narrador. Dessa forma, a expressão minha terra, deve ser interpretada como Brasil; nosso céu, como céu do Brasil e nossas várzeas como várzeas do Brasil.

Reconstruir a cena da enunciação permite que se estabeleça o contexto de produção, pois todo discurso é contextualizado. Maingueneau (2006, p. 42) sustenta que "o discurso não intervém num contexto: só há discurso contextualizado. Além disso, o discurso contribui para definir seu contexto e pode modificá-lo ao longo da enunciação". A abordagem a partir das categorias da enunciação permitiu-nos identificar quem fala e donde fala e se há pertencimento ou não a esse lugar.

O narrador é o sujeito exilado, que fala de um lugar que não é o seu, terra estranha, e fala do exílio enquanto o vivencia, o que o autoriza a falar do que fala. o sujeito fora de lugar quer encontrar seu lugar, que não é o da enunciação (o aqui), mas o lá (o espaço fora da enunciação). Todo o poema se organiza a partir dessa oposição (aqui / lá; não pertencimento / pertencimento), sendo o aqui o espaço do não pertencimento, do sujeito deslocado de seu lugar.

Para a mentalidade romântica, o lugar de pertencimento do sujeito é a pátria e a natureza, sob a inspiração de Deus, por isso a exaltação da natureza pátria e o desejo que Deus possibilite o retorno a ela. Essa exaltação se faz na esteira da oposição aqui / lá, atribuindo o positivo ao lugar de pertencimento (a pátria) e o negativo ao de não pertencimento (o exílio), como mostra o quadro a seguir. 
LÁ

\begin{tabular}{ll}
\multicolumn{1}{c}{ LÁ } & AQUI (CÁ) \\
\hline PERTENCIMENTO & NÃO PERTENCIMENTO \\
\hline MINHA TERRA (BRASIL) & EXÍLIO (PORTUGAL) \\
\hline Palmeiras & não palmeiras \\
\hline Sabiá & não sabiá \\
\hline+ estrelas & - estrelas \\
\hline+ flores & - flores \\
\hline+ vida & - vida \\
\hline+ amores & - amores \\
\hline+ prazer & - prazer \\
\hline Primores & não primores \\
\hline
\end{tabular}

Essa exaltação remete ao discurso nacionalista, próprio do Romantismo.

o poema não termina no seu último verso, tampouco se inicia no primeiro, já que entra na corrente de discursos de saudades da pátria, do exílio, do não pertencimento a um lugar, pois como afirma Maingueneau (2006, p. 42) "[o discurso] só assume um sentido no interior de um universo de outros discursos através do quais deve abrir seu caminho". o discurso literário, ainda segundo Maingueneau, mantém uma relação dupla com o interdiscurso, pois se ele se alimenta de outros textos, expõe-se também à citação por outros.

o poema se abre com um epígrafe de Goethe, em alemão, que, traduzida para o português, diz "Conheces o país onde florescem as laranjeiras? / Ardem na escura fronde os frutos de ouro... /Conhecê-lo? / Para lá, para lá quisera eu ir!". A epígrafe instala o poema na corrente de discursos da pátria e natureza protetoras.

o discurso a que remete a Canção do Exílio prolonga-se em muitos outros textos de nossa literatura. Esse poema é, provavelmente, o texto da literatura brasileira que apresenta o maior número de paródias, entre as quais podemos citar a de Oswald de Andrade ("Minha terra tem Palmares / Onde gorjeia o mar"); a de Murilo Mendes ("Minha terra tem macieiras da Califórnia / Onde cantam gaturamos de Veneza"); a de Mário Quintana ("Minha terra não tem palmeiras... / E em vez de um mero sabiá..."); a de Ferreira Gullar ("Minha amada tem palmeiras / Onde cantam passarinhos"). 0 discurso de regresso à pátria está ainda presente na letra da canção Sabiá, de Tom Jobim e Chico Buarque ("Vou voltar / Sei que ainda vou voltar / Para o meu lugar / Foi lá e é ainda lá / Que eu hei de ouvir cantar / Uma sabiá") e na letra da Canção do Expedicionário, de Guilherme de Almeida, ( "Por mais terras que eu percorra / Não permita Deus que eu morra / Sem que eu volte para lá"). 


\section{LEITURA LITERÁRIA E CONHECIMENTO LINGUÍSTICO: CAMINHOS QUE SE ENTRECRUZAM}

\section{Considerações finais}

Quando se fala em integrar o ensino a partir de áreas de conhecimento (aliás o que já ocorre com o Enem), não há sentido em que o estudo de língua materna seja tripartido em "disciplinas" diferentes, com professores diferentes sem que haja uma fina conexão entre eles. Podemos ter três professores diferentes, mas é condição sine qua non que eles estejam articulados em sua prática pedagógica, de modo que os discursos estejam sintonizados para um objetivo comum.

A proposta deste texto é que as fronteiras entre língua e literatura não criem dois "estados" autônomos; ao contrário, se alguma fronteira existe, que ela não seja impeditiva de se circular de um lado a outro, que se possa ir do território língua ao território literatura sem necessidade de pedir autorização ou de apresentar passaporte. Propomos deixar de lado o estudo da literatura a partir de sua história e passar a estudá-la a partir de suas manifestações concretas, os textos.

Apresentamos uma porta de entrada que, evidentemente, não é a única: estabelecer inicialmente as categorias da enunciação. Dessa forma, sabendo quem fala e de onde fala, os estudantes poderão construir o sentido para os textos que leem e também situá-los na corrente de discursos em que se inserem.

\section{REFERÊNCIAS}

ALMEIDA, Manuel Antônio de. Memórias de um sargento de milícias. Cotia, SP: Ateliê Editorial, 2006.

ANJOS, Augusto dos. Eu: outras poesias. 31a. ed. Rio de Janeiro: 1971.

BANDEIRA, Manuel. Poesia completa e prosa: volume único. Rio de Janeiro: Aguilar, 1974.

BENVENISTE, Émile. Da subjetividade na linguagem. In: ____. Problemas de linguística geral I. 4a. ed. Campinas (SP): Pontes; Editora da Universidade Estadual de Campinas, 1995. [p. 284-293]

. A natureza dos pronomes. In: _____. Problemas de linguística geral I. 4a. ed. Campinas (SP): Pontes; Editora

da Universidade Estadual de Campinas, 1995. [p. 277-283]

[p. 81-90] . O aparelho formal da enunciação. In: . Problemas de linguística geral II. Campinas (SP): Pontes, 1989.

BRASIL. Parâmetros Curriculares Nacionais (Ensino Médio), Parte II: Linguagens, Códigos e suas Tecnologias. Brasília: MEC/SEF, 2000.

DIAS, Gonçalves. Canção do exílio. Apud: CANDIDO, Antonio; CASTELLO, José Aderaldo. Presença da literatura brasileira I - Das origens ao romantismo. $5^{\text {a }}$ ed. São Paulo: Difusão Europeia do Livro, 1973.

LUISELLI, Valeria. Rostos na multidão. Rio de Janeiro: Objetiva, 2012.

MAINGUENEAU, Dominique. Discurso literário. São Paulo: Contexto, 2006. MÁRQUEZ, Gabriel García. Crônica de uma morte anunciada. 36a. ed. Rio de Janeiro: Record, 2007.

MELO, Patrícia. Acqua toffana. Rio de Janeiro: Rocco, 2009.

PESSOA, Fernando. Obra poética: volume único. Rio de Janeiro: José Aguilar Editora, 1972.

TERRA, Ernani. Leitura do texto literário. São Paulo: Contexto, 2014. 